\title{
Atomic force microscopy characterization of
}

\section{biomaterials modified with poly(styrene}

\section{sulfonate)}

Tuan Ngoc Nguyen ${ }^{1}$; Vincent Humblot ${ }^{2}$; Véronique Migonney ${ }^{1^{*}}$; Raphaël Lévy ${ }^{1^{*}}$

${ }^{1}$ Laboratory of Chemistry, Structures, Properties of Biomaterials and Therapeutic Agents, UMR CNRS 7244, Sorbonne Paris Nord University, France

${ }^{2}$ Département Micro Nano Sciences \& Systèmes (MN2S), Equipe BioMicroDevices(BMD), UMR6174-CNRS, Institut FEMTO-ST, France

\section{Authors}

Tuan Ngoc Nguyen : nguyentuan111190@gmail.com; Vincent Humblot:

vincent.humblot@femto-st.fr; Raphaël Lévy : raphael.levy@univ-paris13.fr; Véronique Migonney: veronique.migonney@univ-paris13.fr

\section{Corresponding Authors}

Prof. Raphaël Lévy (raphael.levy@univ-paris13.fr) and Prof. Véronique Migonney (veronique.migonney@univ-paris13.fr): Laboratory of Chemistry, Structures, Properties of Biomaterials and Therapeutic Agents, Université Sorbonne Paris Nord, 99 Avenue JB Clément, 93430 Villetaneuse, France

\begin{abstract}
Polycaprolactone and polyethylene terephthalate are widely used to elaborate biomaterials and medical devices in particular for long-term implant applications but tuning their surface properties remains challenging. We investigate surface functionalization by grafting
\end{abstract}


poly(sodium 4-styrene sulfonate) with the aim of enhancing protein adhesion and cellular activity. Elucidating the topography and molecular level organization of the modified surfaces is important for understanding and predicting biological activity. In this work, we explore several grafting methods including thermal grafting, thermal grafting in the presence of Mohr's salt, and UV activation. We characterize the different surfaces obtained using atomic force microscopy, contact angle and X-ray photoelectron spectroscopy. The results reveal striking differences in the properties of the modified surfaces. This work demonstrates tuning of biomaterials surface by functionalization and the capability of atomic force microscopy to provide insights into the conformation and mechanical properties of the grafted polymers.

Keywords: Peakforce Quantitative Nano-mechanical Properties (PF-QNM); Polyelectrolyte brushes; Polycaprolactone (PCL); Polyethylene Terephthalate (PET); Degradable polymer

\section{Introduction}

Polyesters, in particular polyethylene terephthalate (PET), polycaprolactone (PCL) and their copolymers, are used extensively in tissue engineering and medical devices. Surface functionalization is often required to improve biological properties. Poly (sodium 4-styrene sulfonate) (PNaSS) is a strong polyelectrolyte which has been proposed for the control of biological and biophysical properties including enhancing cell adhesion, spreading, and proliferation, thus improving bone tissue response, ${ }^{1,2}$ fibroblast behavior for reconstructing injured ligament and wound healing, ${ }^{2-4}$ antibacterial infection ${ }^{5}$ and biocompatible surface $^{6,7}$. PNaSS immobilized on different materials such as titanium, ${ }^{6,1,8}$ polyethylene terephthalate $(\mathrm{PET}){ }^{2}$ nanoparticle ${ }^{7,9,10}$ or polycaprolactone $(\mathrm{PCL})^{11}$ has been reported.

Several surface functionalization methods with poly(styrene sulfonate) have been proposed, e.g. sulfonation polystyrene brush and ${ }^{10,12}$ grafting methods..$^{8,11,13}$ Among those, "graftingfrom" has the advantage of being a scalable approach to the modification of interfacial properties through immobilizing the functional groups on the substrate by covalent bonding. The "grafting from" method starts with activation of the surface via plasma, ${ }^{14} \mathrm{UV}$ irradiation, ${ }^{6,15}$ heating, ${ }^{4,11,13}$ in the presence of $\mathrm{CuBr}_{2},{ }^{16-18}$ or Mohr's salt. ${ }^{11,19}$ 
In this work, we activate PET and PCL surfaces by ozonation, a method convenient for materials with complex geometries such as implants. ${ }^{20}$ Ozonation generates peroxide groups which decompose upon heating and UV irradiation ${ }^{13,20,21}$ to generate radicals on PET or PCL. NaSS monomers polymerize from these active sites.

Previous studies examined the effect of the graft PNaSS on the interaction of the modified surfaces with biological molecules yet the characterization of the grafted layer is often limited. Here, we investigate the topography and mechanical properties of grafted polymers by atomic force microscopy (AFM) complemented by XPS and contact angle measurements. We determine the topography and nano-mechanical properties of PNaSS grafted from a biodegradable (PCL) or non-degradable (PET) matrix polymer by different grafting methods.

\section{Materials and Methods}

\subsection{Materials}

Polycaprolactone (PCL) $\left(\mathrm{M}_{\mathrm{n}} 80000 \mathrm{~g} / \mathrm{mol}\right)$, sodium 4- styrene sulfonate (NaSS), phosphate buffer saline (PBS), and Mohr's salt were purchased from Sigma Aldrich. Polyethylene terephthalate (PET) $(0.25 \mathrm{~mm}$, Biaxially Oriented plate was purchased from Goodfellow (Paris, France) and ethanol absolute was from Fisher.

\subsubsection{PET preparation:}

PET plate was cut into small squared pieces $(1 \mathrm{~cm} \times 1 \mathrm{~cm})$. They were washed in $10 \mathrm{~mL}$ ultrapure water, then in $10 \mathrm{~mL}$ acetone, and finally in $10 \mathrm{~mL}$ ethanol for 10 min ultrasonic each time to remove organic compound and impurity on the surface. The samples were dried under vacuum for $2 \mathrm{~h}$ and stored at $4{ }^{\circ} \mathrm{C}$ until use.

\subsubsection{PCL film preparation:}

$\mathrm{PCL}$ solution was prepared by dissolving $1.2 \mathrm{~g} \mathrm{PCL}$ in $3 \mathrm{~mL}$ dichloromethane for $2 \mathrm{~h}$ at room temperature. PCL films were prepared by spin-coating this solution for $30 \mathrm{~s}(1000 \mathrm{rpm})$ at room temperature. They were left overnight and cut into small pieces (14 mm radius).

\subsubsection{Monomer purification:}


The purification of NaSS was described by Migonney et al. ${ }^{4,13,22} 90 \mathrm{~g}$ of NaSS was dissolved in 1.6 $\mathrm{L}$ of ethanol: distilled water $(9: 1, \mathrm{v} / \mathrm{v})$ by stirring $12 \mathrm{~h}$ at $70^{\circ} \mathrm{C}$. Thereafter, the solution was filtered by vacuum filtration. The filtered solution was kept at $4{ }^{\circ} \mathrm{C}$ during $24 \mathrm{~h}$ for recrystallization. Recrystallized monomer was collected by vacuum filtration and was dried in vacuum at $30^{\circ} \mathrm{C}$ for $6 \mathrm{~h}$. Finally, the product was kept at $4{ }^{\circ} \mathrm{C}$, away from the light.

\subsection{Functionalization of polyester surfaces by PNaSS ("grafting from")}

\subsubsection{Activating the surfaces by ozonation}

The functionalization of polyesters by PNaSS includes two main steps: ozonation and grafting (Scheme 1). In the first step, the polymer surfaces were activated by ozonation using ozone generator BMT 802N. 6 polyester films (PCL or PET) were ozonized into $100 \mathrm{~mL}$ distilled water by introducing ozone flow ( 0.6 bars, $100 \mathrm{~mL} / \mathrm{min}$ ) for $10 \mathrm{~min}$ for PCL and 20 min for PET at $30^{\circ} \mathrm{C}^{13}$ Ozonized samples were quickly transferred from the ozonation reactor to the degassed NaSS solution $(0.7 \mathrm{~mol} / \mathrm{L})$ for grafting.

\subsubsection{Grafting PNaSS from polyester substrate}

After activation by ozonation, PNaSS was polymerized from the activated sites (Scheme 1). For determining the influence of ozonation on the surface, the ozonized polymer without grafting, named "non-grafted", sample was used as a reference.

\section{Thermal radical polymerization (method 1 and 2 ):}

Method 1 - Thermal grafting (TG). ${ }^{11,13} 6$ ozonized polyester films (PCL or PET) were transferred into $60 \mathrm{~mL}$ of degassed NaSS $(0.7 \mathrm{~mol} / \mathrm{L})$ solution and heated in an oil bath for 1 $\mathrm{h}$ at $45^{\circ} \mathrm{C}$ for $\mathrm{PCL}$ or $75^{\circ} \mathrm{C}$ for PET. ${ }^{11,13}$ Peroxide decomposition generates the radicals on thus initiating PNaSS polymerization by radical polymerization.

Method 2-Thermal grafting in the presence of Mohr's salt (MSG). 6 ozonized polymer films (PCL or PET) were transferred into $60 \mathrm{~mL}$ degassed mixture solution of $\mathrm{NaSS}(9 \mathrm{~g}, 0.7 \mathrm{~mol} / \mathrm{L})$ and Mohr's salt $(60 \mathrm{mg}, 0.1 \%, \mathrm{w} / \mathrm{v})^{13}$. The reactor was heated to $45^{\circ} \mathrm{C}$ for $\mathrm{PCL}$ or $75^{\circ} \mathrm{C}$ for PET for $1 \mathrm{~h}$. Mohr's salt provides $\mathrm{Fe}^{2+}$ that increases significantly the grafting efficiency. ${ }^{13}$

Photoinitiated free radical polymerization (method 3): 
Method 3-UV irradiation (UVG). ${ }^{21}$ Peroxides were decomposed by UV irradiation. 6 polyester films (PCL or PET) were transferred into $60 \mathrm{~mL}$ of degassed NaSS solution $(9 \mathrm{~g}, 0.7$ $\mathrm{mol} / \mathrm{L}$ ). The solution was irradiated by UV light for $30 \mathrm{~min}$ (lamp UV-Omnicure, $254 \mathrm{~nm}, 10$ $\mathrm{W} / \mathrm{cm}^{2}$ ) at $25^{\circ} \mathrm{C}$ with stirring.

After polymerization via either of the three methods above, free homopolymer, oligomer, and monomer were removed from the grafted samples under stirring in double distilled water for at least $48 \mathrm{~h}$. The washing solution was tested by UV-vis at $360 \mathrm{~nm}$ to check for the presence of any residue of free PNaSS (homopolymer and oligomer). Samples were finally dried under vacuum and kept at $4{ }^{\circ} \mathrm{C}$, away from the light before use.
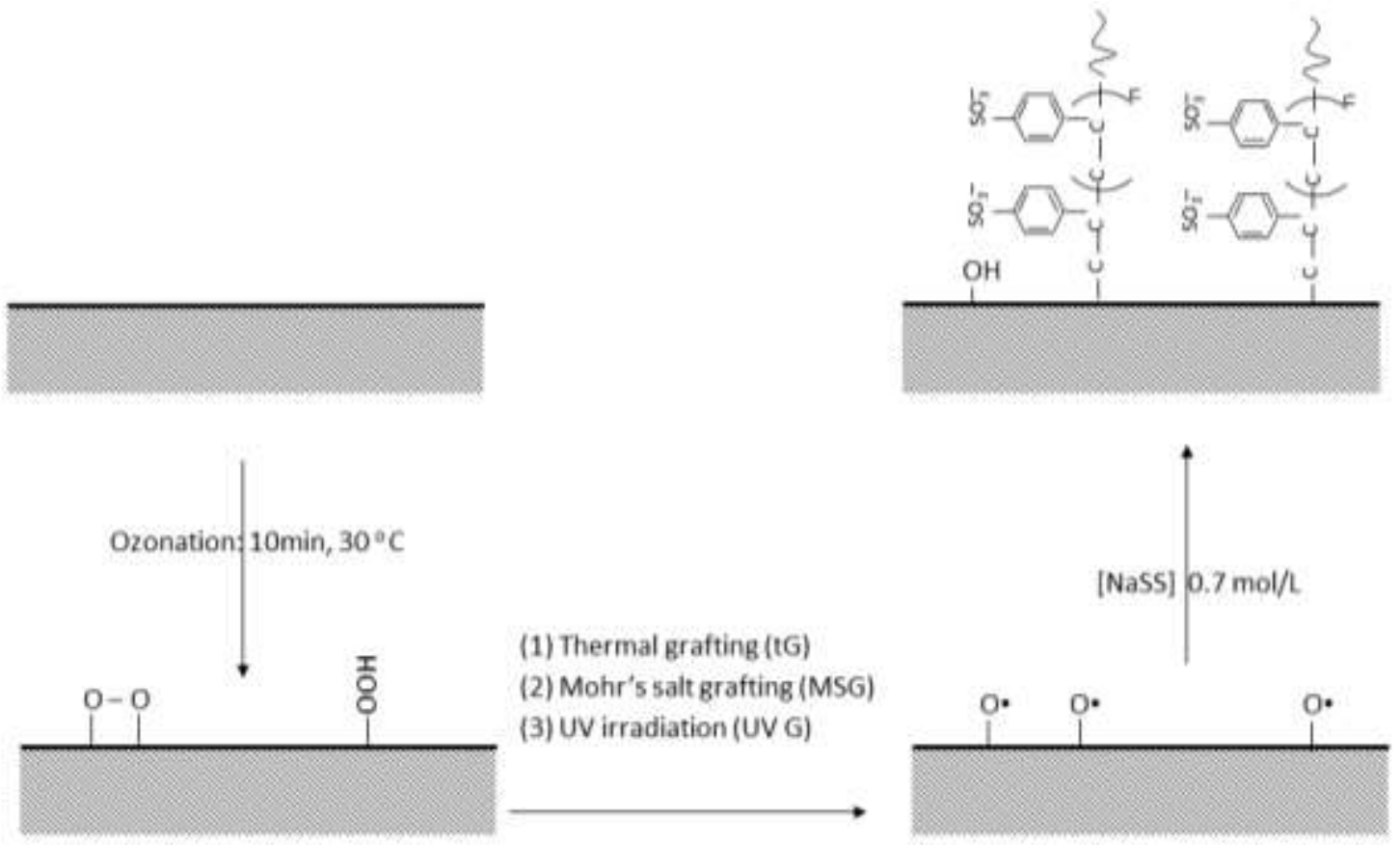

Scheme 1. Grafting PNaSS from polyester surfaces by ozonation and radical polymerization (Polyester $=\mathrm{PET}$ or $\mathrm{PCL})$.

\subsection{Surface characterization}

X-ray photoelectron spectroscopy analysis (XPS). X-ray photoelectron spectroscopy analysis (XPS) (from Omicron Argus spectrometer, Germany) was performed using a monochromated AlKa radiation source $(\mathrm{hv}=1486.6 \mathrm{eV})$ working at an electron beam power of $300 \mathrm{~W}$ with $90^{\circ}$ of takeoff angle of photoelectrons emission, under ultra-high vacuum $\left(\leq 10^{-10}\right.$ Torr). Spectra were recorded at pass energy of $100 \mathrm{eV}$ for the survey spectrum and 
pass energy of $20 \mathrm{eV}$ for the high resolutions regions. Binding energies were calibrated against the C1s binding energy of aliphatic carbon atoms at $284.8 \mathrm{eV}$. Spectral deconvolution was carried out using Casa XPS v.2.3.15 software (Casa Software Ldt, UK). All samples were dry films.

Contact angle. DSA10 contact angle system from KRUSS GmbH was used to measure the surface tension by the sessile drop technique. Two solvents: water (polar), and diiodomethane (unpolar) $\left(2 \mu \mathrm{L}, 25{ }^{\circ} \mathrm{C}, 8 \mathrm{~s}\right)$ were used. The surface tension of polymer $\left(\gamma_{\mathrm{s}}\right)$ was calculated by Young-Dupre and Fowker's equation.

Atomic Force Microscopy. Atomic force microscope (AFM) multimode-8 from Bruker was used. AFM scans were carried out in air using Scanasyst probe (absolute calibration was performed, symmetric tip with radius $\leq 10 \mathrm{~nm}, \mathrm{f}_{0}: 70 \mathrm{KHz}$, spring constant: $\sim 0.4 \mathrm{~N} / \mathrm{m}$ ), scan rate $1 \mathrm{~Hz}$, at different scan sizes: $500 \mathrm{~nm} \times 500 \mathrm{~nm}, 2 \mu \mathrm{m} \times 2 \mu \mathrm{m}$ (3 samples).

Nano-Scope Analysis v.1.5, Image-J and AtomicJ software ${ }^{23}$ were used for image analysis. Surface mechanical properties was measured by Peakforce Quantitative Nano-mechanical Properties (PF-QNM) program. ${ }^{24}$ when number of samples are indicated, they refer to independent experiments (from sample preparation).

\section{Results and discussion}

\subsection{Surface characterization}

As a NaSS unit contains one atom of sulfur, the surface density of grafted PNaSS can be estimated based on the percentage of sulfur atoms in the elementary composition using XPS. Sulfur was not detected on the non-grafted-ozonized PCL and PET surfaces, but the S2p peak was visible $(165-170 \mathrm{eV})^{25}$ on the six grafted surfaces (see spectra in Figure S1). For both PCL and PET, the quantification of those contributions indicated that the monomer surface density was much lower in the case of the thermal grafting than for the UV and Mohr's salt catalyzed grafting (Figure 2A).

Specifically, for PET, the S/C ratio for the UV and Mohr's salt samples was more than ten times higher than for thermal grafting (Figure 2A). The PNaSS surface density (SD) by UV 
irradiation was higher than when using Mohr's salt. The ranking was $\mathrm{SD}_{\mathrm{TG}-\mathrm{PET}}<\mathrm{SD}_{\mathrm{MSG}-\mathrm{PET}}<$ SDUVG-PET.

For PCL, UVG and MSG provided more than five times higher PNaSS surface density than thermal grafting (Figure 2A). Therefore, XPS enabled us to rank the three methods by increasing PNaSS surface density as follows: $\mathrm{SD}_{\mathrm{TG}-\mathrm{PCL}}<\mathrm{SD}_{\mathrm{UVG}-\mathrm{PCL}}<\mathrm{SD}_{\mathrm{MSG}-\mathrm{PCL}}$.

The surfaces were more hydrophilic after functionalization (Figure S2) and the surface energy correlated to the XPS results. The surface tension $\left(\gamma_{S}\right)$ of functionalized surfaces was measured by the contact angle method (Figure 2B). Non-grafted and TG samples were similar: $\sim 45-48 \mathrm{mN} / \mathrm{m}$ for PET and $\sim 47-50 \mathrm{mN} / \mathrm{m}$ for PCL. However, surface tension increased significantly on UVG samples. Particularly, $\gamma_{\mathrm{S}}$ of UVG-PET increased by $54 \%$ (73 $\mathrm{mN} / \mathrm{m}$ ) and $8 \%$ for MSG-PET ( $52 \mathrm{mN} / \mathrm{m}$ ). Whilst, it increased by $60 \%$ for MSG-PCL ( 76 $\mathrm{mN} / \mathrm{m})$, and about $28 \%$ for UVG-PCL $(\sim 61 \mathrm{mN} / \mathrm{m})$. These variations correlated to the amount of $\mathrm{SO}_{3}{ }^{-}$groups (\% Sulfur by XPS) on the surface leading to the increase of surface tension (represented by the S/C ratio in Figure 2A) although for the PET Mohr's salt condition the increase of surface tension were small.
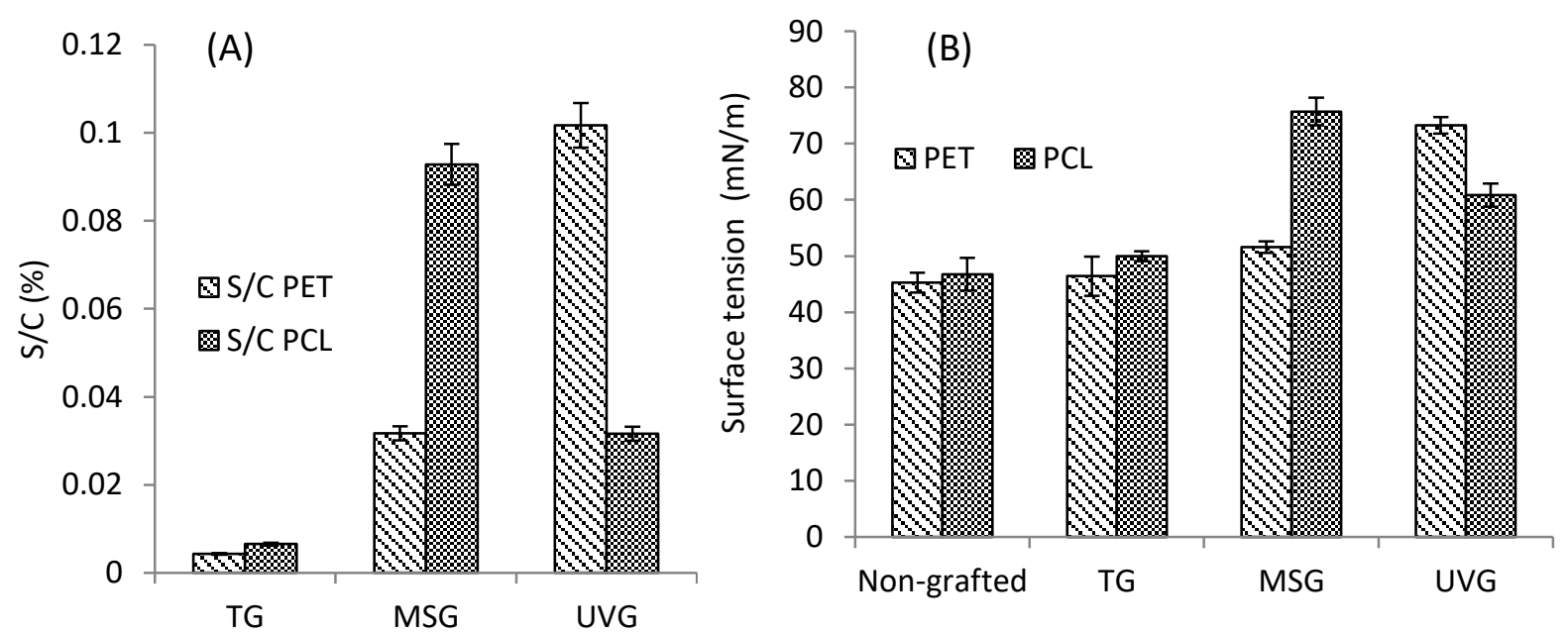

Figure 2. Surface characterization of non-grafted-ozonized and grafted PET and PCL: (a) S/C ratio from XPS data and (b) surface tension by contact angle

\subsection{PNaSS structures on polyester surfaces after grafting}

Atomic Force Microscopy (AFM) can be used as a non-destructive method to analyze polymer surfaces. ${ }^{26-30}$ Numerous parameters can be investigated, e.g. the macromolecule 
structure, $^{16}$ thickness, ${ }^{31-36}$ and adhesion. PNaSS grafted surfaces of PCL and PET were investigated by AFM peak force Quantitative nanomechanical properties (PF-QNM) in air at room temperature and compared to non-grafted- ozonized surface (without PNaSS grafting). Adhesion maps measure the interaction between the AFM tip and the material : they can therefore provide clues as to the local chemical nature of the surface. ${ }^{37}$

\subsubsection{PNaSS Grafted polyethylene terephthalate (PET)}

Non-grafted- ozonized PET was prepared by ozonation of a PET plate for $20 \mathrm{~min}$ at $30{ }^{\circ} \mathrm{C}$ without PNaSS grafting. The surface topography and adhesion images of non-grafted PET were used as a reference. The AFM images of the PET surfaces obtained after PNaSS grafting by the three methods are shown in Figure 3 and briefly described below.

\section{Thermal radical polymerization:}

Thermal grafting. The TG-PET surface topography and adhesion were similar to the ozonized surface (Figure 3A-B). This was in agreement with the XPS and contact angle results which suggested a low degree of grafting. The surface roughness of TG-PET (Sa = $1.03 \pm 0.24 \mathrm{~nm}, \mathrm{n}=3$ ) remained identical to non-grafted PET (Sa $=1.12 \pm 0.18 \mathrm{~nm}, \mathrm{n}=3$ ).

Thermal grafting in the presence of Mohr's salt. The topography of MSG-PET appeared similar but the surface roughness ( $\mathrm{Sa}=3.33 \pm 0.09 \mathrm{~nm}$ ) increased by a factor 3 (Figure 3C). 


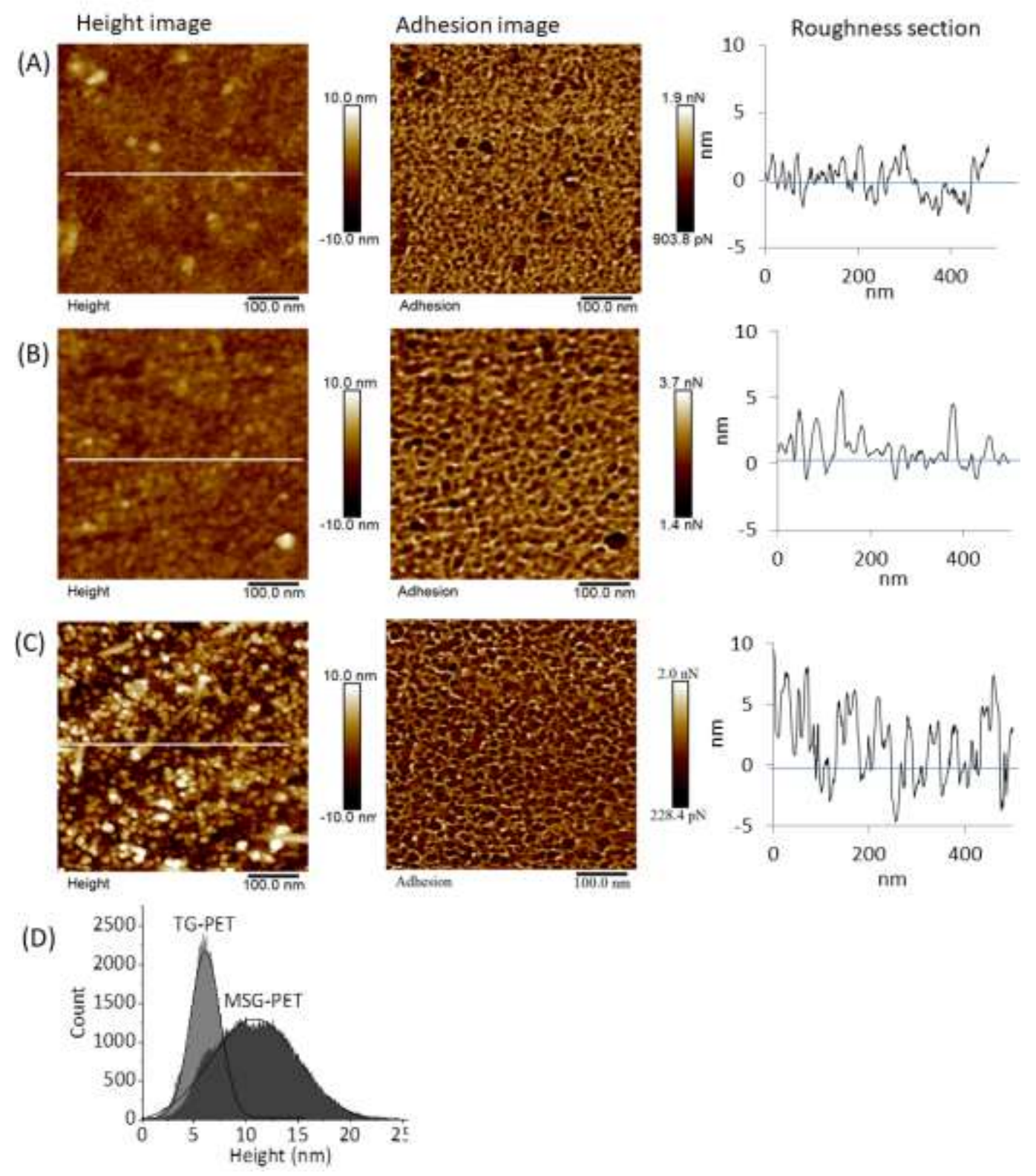

Figure 3. AFM images of non-grafted and thermal grafted PET, scan in air: (A) non-grafted PET (Ozonized PET without grafting), (B) thermal grafted (TG) PET, (C) thermal grafting in the presence of Mohr's salt (MSG) PET, (D) Height distribution of TG and MSG-PET; scan size 500 $\mathrm{nm} \times 500 \mathrm{~nm}, 256$ points/line, scan rate $1 \mathrm{~Hz}, \mathrm{PF}-\mathrm{QNM}$

\section{Photoinitiated radical polymerization:}

UV grafting (UVG). Remarkably, in the case of UV grafting, both topography and adhesion images (Figure $4 A, C$ ) were drastically different from what had been observed in the other cases. The surface was extremely smooth with sub-nm variations in thickness over areas of 
hundreds of $\mathrm{nm}^{2}$. Furthermore, as shown by the profile line, patches with boundaries defined by steps of $\sim 1 \mathrm{~nm}$ height were observed (roughness section, Figure 4B). Those patches were striking in the adhesion images (Figure 4C), reduced adhesion on the patches (Figure 4D). This suggested that a form of self-assembly of the polymer layer is taking place, with probably a different molecular configuration presented on the patches.

(A)

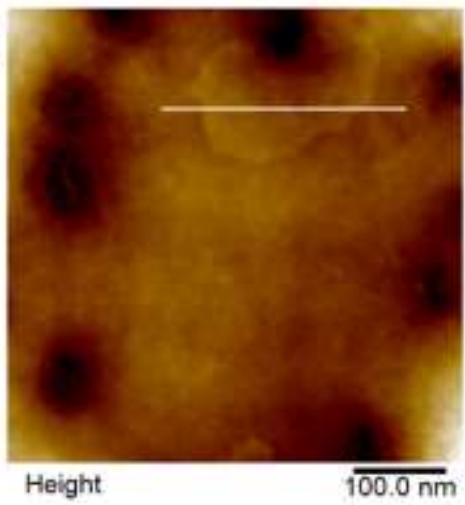

(C)

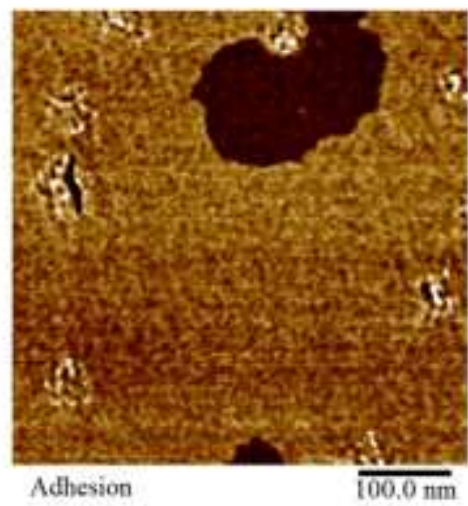

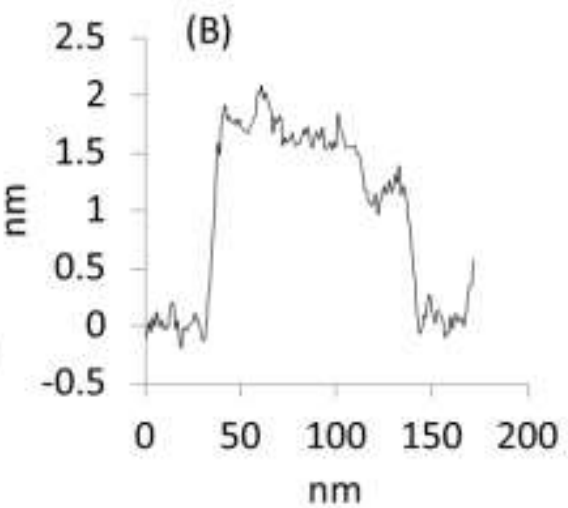

(D)
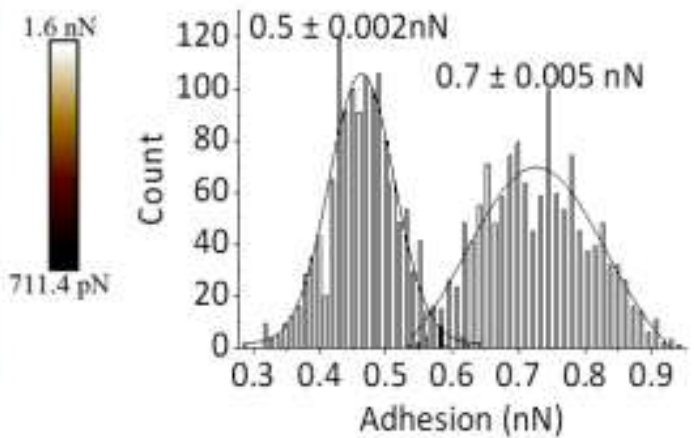

Figure 4. AFM images of UV grafted PET (A) height image, (B) roughness section from the section lines on height images, (C) adhesion map, and (D) Adhesion force distribution (flat surface, patches); scan size $500 \mathrm{~nm} \times 500 \mathrm{~nm}, 256$ points/line, scan rate $1 \mathrm{~Hz}$, PF-QNM

\subsection{2. $\mathrm{PNaSS}$ grafted polycaprolactone (PCL)}

$\mathrm{PCL}$ is a semicrystalline polymer - which structure includes crystalline and amorphous regions. ${ }^{11}$ Lamellar regions were observed on non-grafted PCL both in topography and adhesion images (Figure 5A). The AFM images of three functionalized PCL surfaces were markedly different from non-grafted surface.

Thermal radical polymerization: 
Thermal grafting. The TG-PCL topography image (Figure 5B) showed the appearance of circular or elongated domains on lamellar crystalline after grafting with size distribution of 7-10 nm of height which covered about $20 \%$ of the area (evaluated using Image J). It seems that polymerization is mostly happening from the edges of the underlying lamellar domains, which can still be seen in Figure 5C. Those domains were also clearly visible as regions of reduced adhesion.

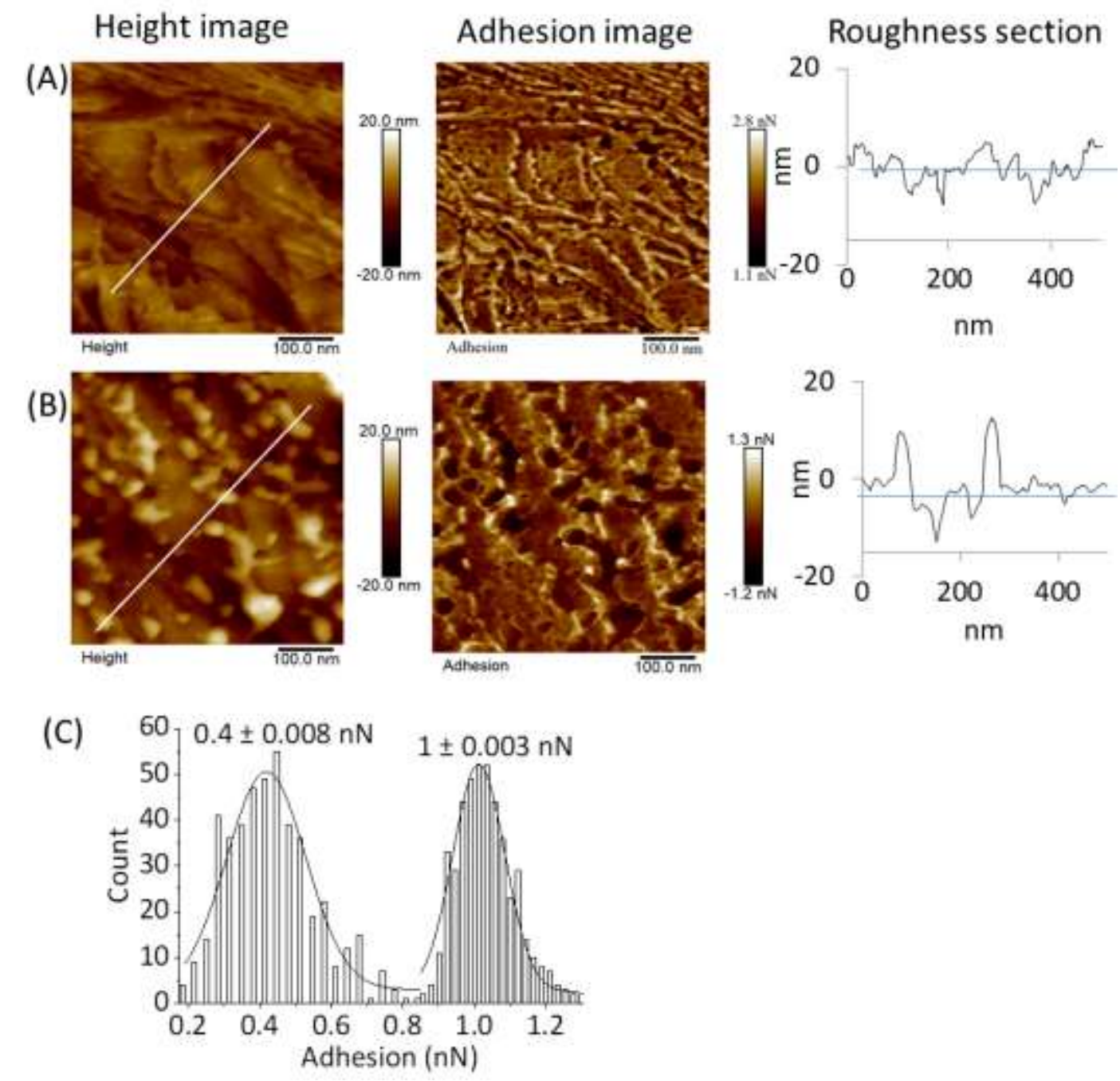

Figure 5. $A F M$ images of functional $P C L$ scan in air: $(A)$ non-grafted $P C L$ (Ozonized $P C L$ without grafting), (B) thermal grafted (TG) PCL, (C) adhesion distribution on TG-PCL (lamellar surface, domains); Roughness sections were determined from the section lines on height images; $500 \mathrm{~nm} \times 500 \mathrm{~nm}, 256$ points/line, scan rate $1 \mathrm{~Hz}$ 
Thermal grafting in the presence of Mohr's salt. The topography image of MSG-PCL suggested the formation of a very smooth film with some defects revealing the underlying PCL structure. This interpretation was comforted by the adhesion images with features comparable to the non-grafted- ozonized surfaces visible in those holes (whereas the film itself shows a highly uniform adhesion value). If this interpretation is correct then one can estimate the thickness of the film to be of the order of 5-7 nm based on the step in Figure $6 \mathrm{~A}$.

\section{Photoinitiated radical polymerization:}

UV grafting. Similar features to MSG-PCL were observed with UVG-PCL. Patches of a flat and homogeneous film covered the lamellar structure of the PCL (Figure 5B). The patches' thickness seems to be of the order of $\sim 10 \mathrm{~nm}$ thick (see profile, Figure 5B).

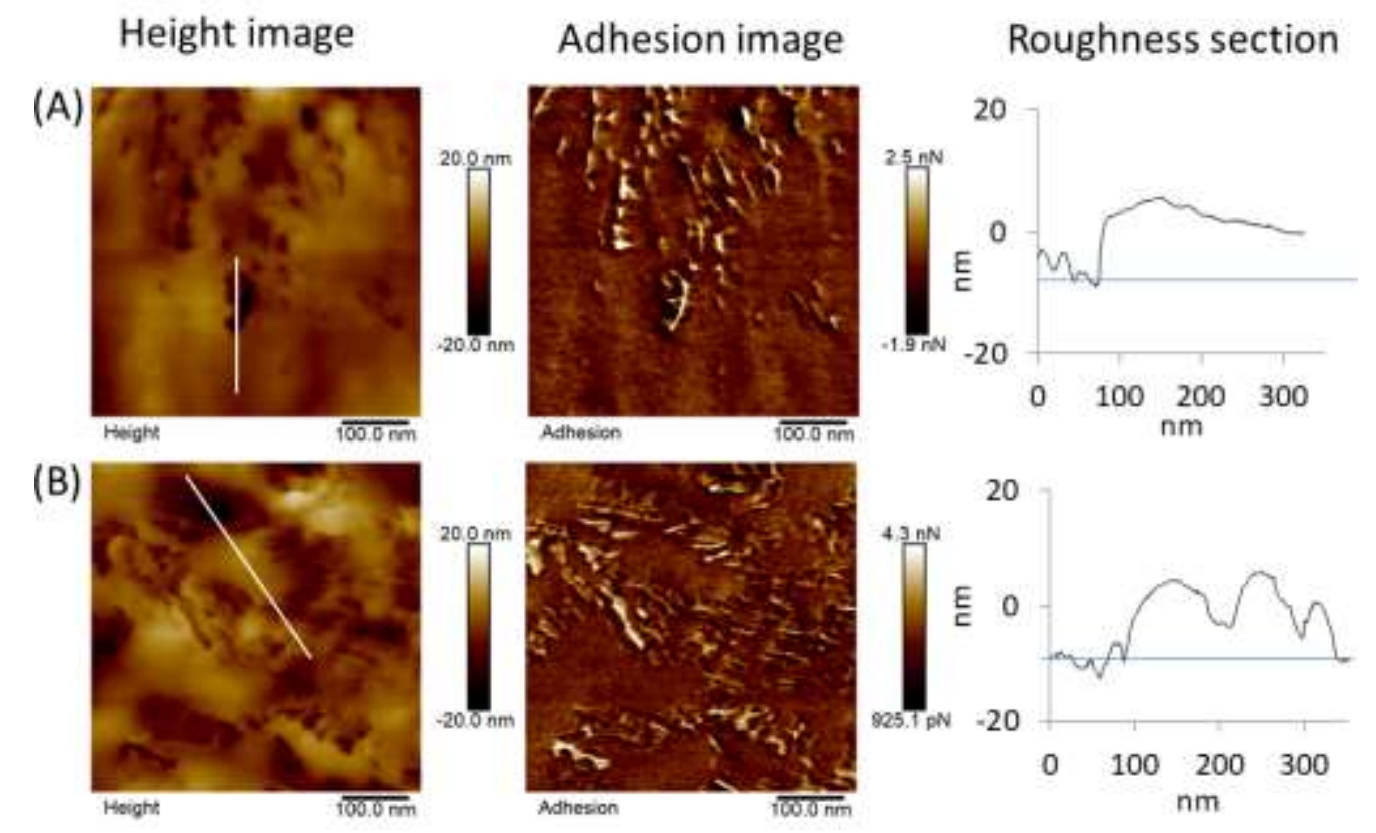

Figure 6. AFM images of (A) Thermal grafting in the presence of Mohr's salt (MSG) PCL, and (B) UV grafted PCL; $500 \mathrm{~nm} \times 500 \mathrm{~nm}, 256$ points/line, scan rate $1 \mathrm{~Hz}$

The combination of the XPS, surface tension and AFM images provides a consistent picture of the grafted surfaces. Thus, the thermal grafting results indicate a low coverage (XPS results, Figure $2 \mathrm{~A}$ ) on both PET and PCL although significantly higher on PCL than PET. This correlates with the surface tension measurements where we do no observe significant 
changes from the unmodified surfaces (Figure 2B). The AFM images of those surfaces do not allow visualization of the PNaSS in the case of PET whilst it is visible, in the form of domains that occupy $\sim 20 \%$ of the surface in the case of PCL. The absence of detectable change in the case of PET is probably due to a combination of low grafting (as indicated by XPS and surface tension) and of the fact that the non-grafted -ozonized PET surface is already rough making it harder to detect small changes.

In the case of thermal grafting in the presence of Mohr's salt, XPS and surface tension measurements correlate and both point to an increased surface density, especially for the PCL surface. The AFM images are consistent and complementary with those larger scale measurements. In the case of PET, they show an increased roughness: a plausible interpretation would be that polymerization occurs preferentially on the "hills" thus amplifying the surface roughness. ${ }^{37}$ In the case of PCL, a flat and homogeneous film is now covering almost the entire surface. The peroxides after decomposition form two types of free radicals, $\mathrm{OH}$ and $\mathrm{O} \cdot$, and then $\mathrm{C}^{\circ}$ (carbonyl) radicals ${ }^{20}$ on the polymer chains. Free radicals ${ }^{\circ} \mathrm{OH}$ are consumed by $\mathrm{Fe}^{2+}$ in Mohr's salt, thus reducing homopolymerization and promoting grafting. ${ }^{13,38,39}$

Finally, in the case of photoinitiated radical polymerization (UV grafting), again XPS and surface tension measurements correlate (Figure 2). Compared to Mohr's salt, they point to an increased PNaSS surface density for PET and a reduced one for PCL. The AFM is consistent with those measurements in the case of PET with a homogeneous film now covering the surface. A film is also observed in the case of PCL but it seems more fragmented than the Mohr's salt condition.

\section{Conclusion}

The results provide insights into the morphology of PNaSS grafted from two polymers that are commonly used in biomedical engineering by harnessing a combination of AFMPeakforce quantitative nanomechanical properties with XPS and contact angle measurements. It also suggests the existence of nanometer scale self-assembly within dry PNaSS films; the molecular level understanding of these arrangements will need to be explored in further work.

\section{Funding Sources}


This work was funded as part of the "Future Investment Project" by the French Public Investment Bank (BPI) and the French state - PSPC application - Liga2bio project.

\section{References}

(1) Felgueiras, H. P.; Sommerfeld, S. D.; Murthy, N. S.; Kohn, J.; Migonney, V. Poly(NaSS) Functionalization Modulates the Conformation of Fibronectin and Collagen Type i to Enhance Osteoblastic Cell Attachment onto Ti6Al4V. Langmuir 2014, 30 (31), 94779483. https://doi.org/10.1021/la501862f.

(2) Vaquette, C.; Viateau, V.; Guérard, S.; Anagnostou, F.; Manassero, M.; Castner, D. G.; Migonney, V. The Effect of Polystyrene Sodium Sulfonate Grafting on Polyethylene Terephthalate Artificial Ligaments on Invitro Mineralisation and Invivo Bone Tissue Integration. Biomaterials 2013, 34 (29), 7048-7063. https://doi.org/10.1016/j.biomaterials.2013.05.058.

(3) Elbert, D. L.; Herbert, C. B.; Hubbell, J. A. Thin Polymer Layers Formed by Polyelectrolyte Multilayer Techniques on Biological Surfaces. Langmuir 1999, 15 (16), 5355-5362. https://doi.org/10.1021/la9815749.

(4) Ciobanu, M.; Siove, A.; Gueguen, V.; Gamble, L. J.; Castner, D. G.; Migonney, V. Radical Graft Polymerization of Styrene Sulfonate on Poly(Ethylene Terepthalate) Films for ACL Applications: "Grafting from" and Chemical Characterization. Biomacromolecules 2006, 7 (3), 755-760. https://doi.org/10.1021/bm050694+.

(5) Simoes, J. A.; Citron, D. M.; Aroutcheva, A.; Anderson, R. A.; Chany, C. J.; Waller, D. P.; Faro, S.; Zaneveld, L. J. D. Two Novel Vaginal Microbicides (Polystyrene Sulfonate and Cellulose Sulfate) Inhibit Gardnerella Vaginalis and Anaerobes Commonly Associated with Bacterial Vaginosis. Antimicrob. Agents Chemother. 2002, 46 (8), 2692-2695. https://doi.org/10.1128/AAC.46.8.2692-2695.2002.

(6) Chouirfa, H.; Evans, M. D. M.; Bean, P.; Saleh-Mghir, A.; Crémieux, A. C.; Castner, D. G.; Falentin-Daudré, C.; Migonney, V. Grafting of Bioactive Polymers with Various Architectures: A Versatile Tool for Preparing Antibacterial Infection and Biocompatible Surfaces. ACS Appl. Mater. Interfaces 2018, 10 (2), 1480-1491. https://doi.org/10.1021/acsami.7b14283. 
(7) Girard, J.; Brunetto, P. S.; Braissant, O.; Rajacic, Z.; Khanna, N.; Landmann, R.; Daniels, A. U.; Fromm, K. M. Development of a Polystyrene Sulfonate/Silver Nanocomposite with Self-Healing Properties for Biomaterial Applications. Comptes Rendus Chim. 2013, 16 (6), 550-556. https://doi.org/10.1016/j.crci.2013.04.010.

(8) Chouirfa, H.; Evans, M. D. M.; Castner, D. G.; Bean, P.; Mercier, D.; Galtayries, A.; Falentin-Daudré, C.; Migonney, V. Grafting of Architecture Controlled Poly(Styrene Sodium Sulfonate) onto Titanium Surfaces Using Bio-Adhesive Molecules: Surface Characterization and Biological Properties. Biointerphases 2017, 12 (2), 02 C418. https://doi.org/10.1116/1.4985608.

(9) Harris, C. M.; Miller, S. G.; Andresen, K.; Thompson, L. B. Quantitative Measurement of Sodium Polystyrene Sulfonate Adsorption onto CTAB Capped Gold Nanoparticles Reveals Hard and Soft Coronas. J. Colloid Interface Sci. 2018, 510, 39-44. https://doi.org/10.1016/j.jcis.2017.08.085.

(10) Su, N.; Li, H. B.; Zheng, H. M.; Yi, S. P.; Liu, X. H. Synthesis and Characterization of Poly(Sodium-p-Styrenesulfonate)/Modified SiO 2 Spherical Brushes. Express Polym. Lett. 2012, 6 (8), 680-686. https://doi.org/10.3144/expresspolymlett.2012.72.

(11) Rohman, G.; Huot, S.; Vilas-Boas, M.; Radu-Bostan, G.; Castner, D. G.; Migonney, V. The Grafting of a Thin Layer of Poly(Sodium Styrene Sulfonate)onto Poly( $\varepsilon$ Caprolactone) Surface Can Enhance Fibroblast Behavior.Pdf. J Mater Sci Mater Med. 2015, 26 (7), 5539. https://doi.org/10.1007/s10856-015-5539-7.

(12) Moujahid, E. M.; Besse, J. P.; Leroux, F. Synthesis and Characterization of a Polystyrene Sulfonate Layered Double Hydroxide Nanocomposite. In-Situ Polymerization vs. Polymer Incorporation. J. Mater. Chem. 2002, 12 (11), 3324-3330. https://doi.org/10.1039/b205837p.

(13) Nguyen, N. T.; Rangel, A.; Migonney, V. Kinetic and Degradation Reactions of Poly (Sodium 4-Styrene Sulfonate) Grafting "from" Ozonized Poly ( $\varepsilon$-Caprolactone) Surfaces. Polym. Degrad. Stab. 2020, 109154. https://doi.org/https://doi.org/10.1016/j.polymdegradstab.2020.109154.

(14) Lego, B.; Skene, W. G.; Giasson, J. S. Unprecedented Covalently Attached ATRP 
Initiator onto OH-Functionalized Mica Surfaces. Langmuir 2008, 24 (2), 379-382. https://doi.org/10.1021/la703051b.

(15) Mathis, C. H.; Simič, R.; Kang, C.; Ramakrishna, S. N.; Isa, L.; Spencer, N. D. Indenting Polymer Brushes of Varying Grafting Density in a Viscous Fluid: A Gradient Approach to Understanding Fluid Confinement. Polymer (Guildf). 2019, 169 (February), 115123. https://doi.org/10.1016/j.polymer.2019.02.040.

(16) Yamamoto, S.; Ejaz, M.; Tsujii, Y.; Fukuda, T. Surface Interaction Forces of WellDefined, High-Density Polymer Brushes Studied by Atomic Force Microscopy. 2. Effect of Graft Density. Macromolecules 2000, 33 (15), 5608-5612.

https://doi.org/10.1021/ma991988o.

(17) Yamamoto, S.; Tsujii, Y.; Fukuda, T. Atomic Force Microscopic Study of Stretching a Single Polymer Chain in a Polymer Brush. Macromolecules 2000, 33 (16), 5995-5998. https://doi.org/10.1021/ma000225u.

(18) Jones, D. M.; Brown, A. A.; Huck, W. T. S.; Street, P.; Cb, C. Surface-Initiated Polymerizations in Aqueous Media: Effect of Initiator Density Darren. Langmuir 2002, No. $13,1265-1269$.

(19) Nguyen, N. T.; Rangel, A.; Migonney, V. Kinetic and Degradation Reactions of Poly (Sodium 4-Styrene Sulfonate) Grafting "from" Ozonized Poly ( $\varepsilon$-Caprolactone) Surfaces. Polym. Degrad. Stab. 2020, 176, 109154. https://doi.org/10.1016/j.polymdegradstab.2020.109154.

(20) Fujimoto, K.; Takebayashi, Y.; Inoue, H.; Ikada, Y. Ozone-induced Graft Polymerization onto Polymer Surface. J. Polym. Sci. Part A Polym. Chem. 1993, 31 (4), 1035-1043. https://doi.org/10.1002/pola.1993.080310426.

(21) Amokrane, G.; Falentin-Daudré, C.; Ramtani, S.; Migonney, V. A Simple Method to Functionalize PCL Surface by Grafting Bioactive Polymers Using UV Irradiation. Irbm 2018, 39 (4), 268-278. https://doi.org/10.1016/j.irbm.2018.07.002.

(22) Pavon-Djavid, G.; Gamble, L. J.; Ciobanu, M.; Gueguen, V.; Castner, D. G.; Migonney, V. Bioactive Poly(Ethylene Terephthalate) Fibers and Fabrics: Grafting, Chemical Characterization, and Biological Assessment. Biomacromolecules 2007, 8 (11), 3317- 
3325. https://doi.org/10.1021/bm070344i.

(23) Hermanowicz, P.; Sarna, M.; Burda, K.; Gabryś, H. AtomicJ: An Open Source Software for Analysis of Force Curves. Rev. Sci. Instrum. 2014, 85 (6).

https://doi.org/10.1063/1.4881683.

(24) Pittenger, B.; Erina, N.; Su, C. Quantitative Mechanical Property Mapping at the Nanoscale with PeakForce QNM. Bruker Application Note AN128. 2010. https://doi.org/10.13140/RG.2.1.4463.8246.

(25) Goh, S. H.; Lee, S. Y.; Zhou, X.; Tan, K. L. X-Ray Photoelectron Spectroscopic Studies of Interactions between Styrenic Polymers and Poly(2,6-Dimethyl-1,4-Phenylene Oxide). Macromolecules 1999, 32 (3), 942-944. https://doi.org/10.1021/ma980920q.

(26) Nair, S. S.; Wang, C.; Wynne, K. J. AFM Peakforce QNM Mode for Measurement of Nanosurface Mechanical Properties of Pt-Cured Silicones. Prog. Org. Coatings 2019, 126 (October 2018), 119-128. https://doi.org/10.1016/j.porgcoat.2018.10.008.

(27) Young, T. J.; Monclus, M. A.; Burnett, T. L.; Broughton, W. R.; Ogin, S. L.; Smith, P. A. The Use of the PeakForceTM Quantitative Nanomechanical Mapping AFM-Based Method for High-Resolution Young's Modulus Measurement of Polymers. Meas. Sci. Technol. 2011, 22 (12). https://doi.org/10.1088/0957-0233/22/12/125703.

(28) Dokukin, M. E.; Sokolov, I. Quantitative Mapping of the Elastic Modulus of Soft Materials with HarmoniX and PeakForce QNM AFM Modes. Langmuir 2012. https://doi.org/10.1021/la302706b.

(29) Pittenger, B.; Erina, N.; Su, C. Quantitative Mechanical Property Mapping at the Nanoscale with PeakForce QNM. Bruker Appl. Note AN128 2010, AN128 (April 2015). https://doi.org/10.13140/RG.2.1.4463.8246.

(30) Kaemmar, S. B. Introduction to Bruker's ScanAsyst and PeakForce Tapping AFM Technology. Appl. note 2011, 133 (Rev. A0), 12.

(31) Sui, X.; Zapotoczny, S.; Benetti, E. M.; Schön, P.; Vancso, G. J. Characterization and Molecular Engineering of Surface-Grafted Polymer Brushes across the Length Scales by Atomic Force Microscopy. J. Mater. Chem. 2010, 20 (24), 4981-4993. 
https://doi.org/10.1039/b924392e.

(32) Chen, W. L.; Cordero, R.; Tran, H.; Ober, C. K. 50th Anniversary Perspective: Polymer Brushes: Novel Surfaces for Future Materials. Macromolecules 2017, 50 (11), 40894113. https://doi.org/10.1021/acs.macromol.7b00450.

(33) Halperin, A.; Zhulina, E. B. Atomic Force Microscopy of Polymer Brushes: Colloidal versus Sharp Tips. Langmuir 2010, 26 (11), 8933-8940.

https://doi.org/10.1021/la9047374.

(34) Phillips, R. W. Atomic Force Microscopy for Thin Film Analysis. Surf. Coatings Technol. 1994, 68-69 (C), 770-775. https://doi.org/10.1016/0257-8972(94)90251-8.

(35) Lego, B.; Skene, W. G.; Giasson, S. Swelling Study of Responsive Polyelectrolyte Brushes Grafted from Mica Substrates: Effect of PH, Salt, and Grafting Density. Macromolecules 2010, 43 (9), 4384-4393. https://doi.org/10.1021/ma902588j.

(36) Variola, F. Atomic Force Microscopy in Biomaterials Surface Science. Phys. Chem. Chem. Phys. 2015, 17 (5), 2950-2959. https://doi.org/10.1039/c4cp04427d.

(37) Zalakain, I.; Politakos, N.; Ramos, J. A.; Saralegi, A.; Etxeberria, H.; Mondragon, I.; Corcuera, M. A.; Eceiza, A. Chemical and Morphological Characterization of Sulfonated Polystyrene Brushes in Different Environments. Eur. Polym. J. 2013, 49 (8), 2120-2127. https://doi.org/10.1016/j.eurpolymj.2013.04.025.

(38) Ishigaki, I.; Sugo, T.; Takayama, T.; Okada, T.; Okamoto, J.; Machi, S. Graft Polymerization of Acrylic Acid onto Polyethylene Film by Preirradiation Method. II. Effects of Oxygen at Irradiation, Storage Time after Irradiation, Mohr's Salt, and Ethylene Dichloride. J. Appl. Polym. Sci. 1982, 27 (3), 1043-1051. https://doi.org/10.1002/app.1982.070270323.

(39) Fujimoto, K.; Tadokoro, H.; Ueda, Y.; Ikada, Y. Polyurethane Surface Modification by Graft Polymerization of Acrylamide for Reduced Protein Adsorption and Platelet Adhesion. Biomaterials 1993, 14 (6), 442-448. https://doi.org/10.1016/01429612(93)90147-T. 


\section{Supporting information}
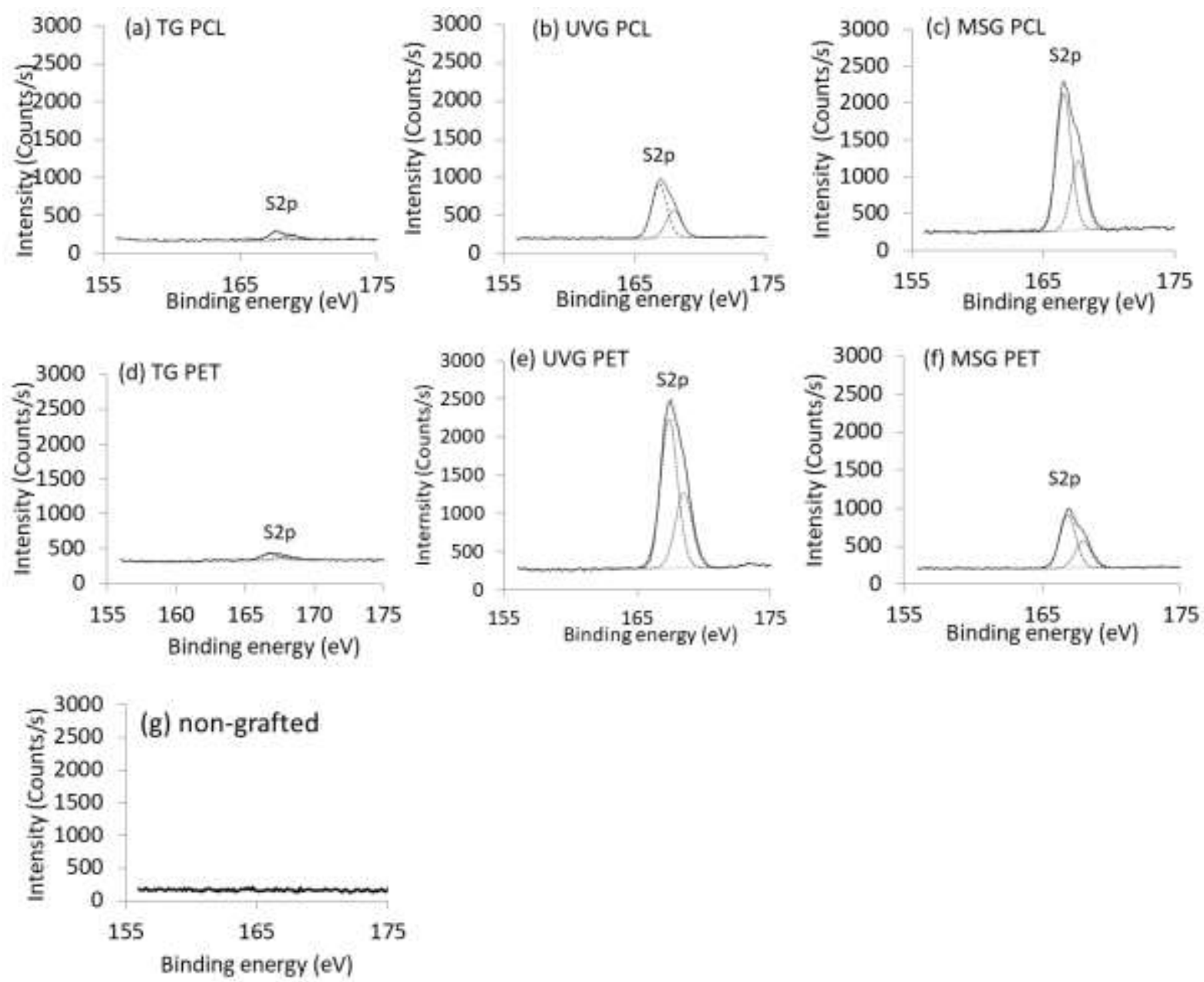

Figure S1. XPS spectra of functional PCL and PET: (a) thermal graft PCL surface, (b) UV graft PCL surface, (c) MS graft PCL surface, (d) thermal graft PET surface, (e) UV graft PET surface, and (f) MS graft PET surface 


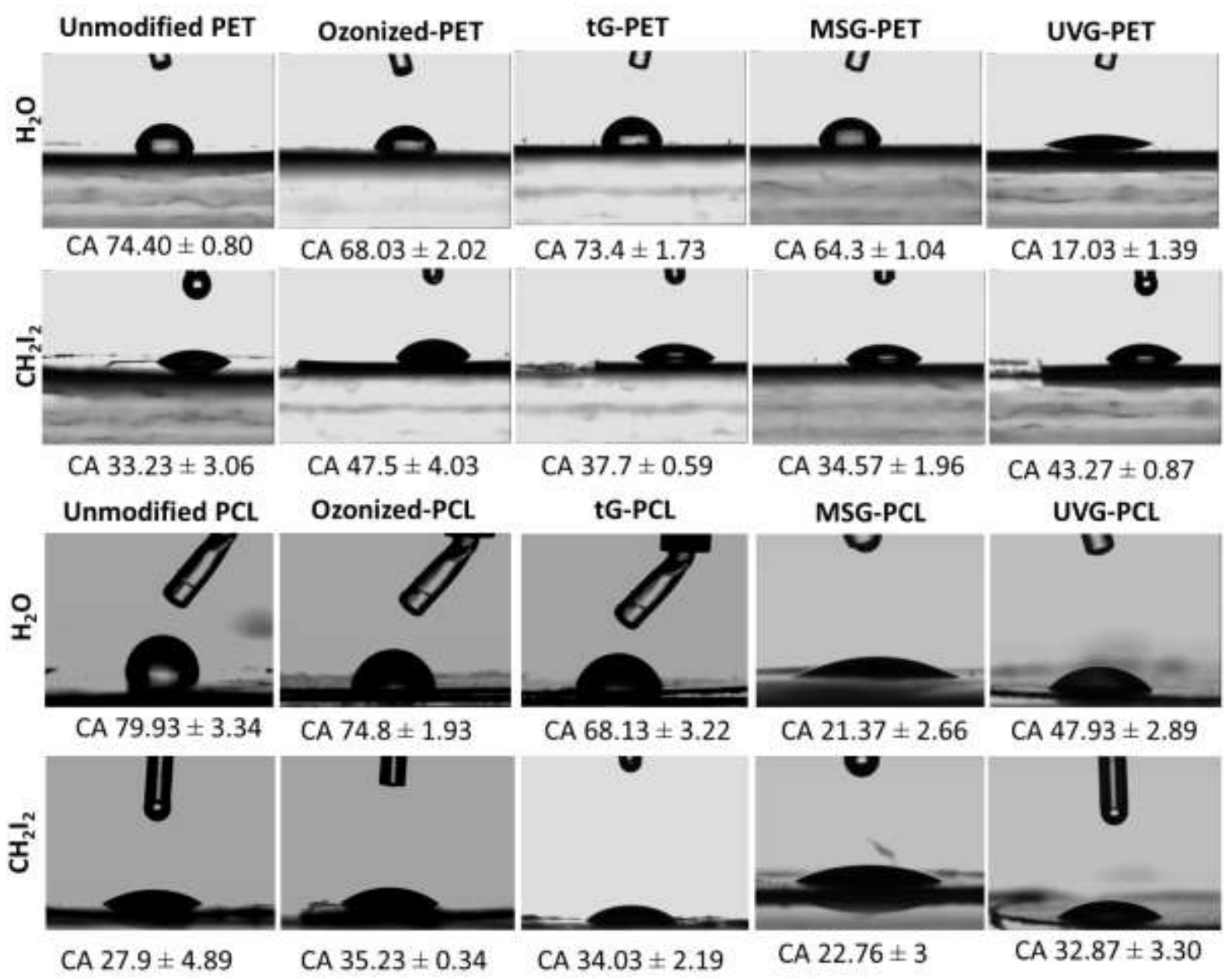

Figure S2. Contact angle measurement $(2 \mu \mathrm{L}, 8 \mathrm{~s})$ for non-grafted and modified polyethylene terephthalate (PET) and polycaprolactone (PCL) 

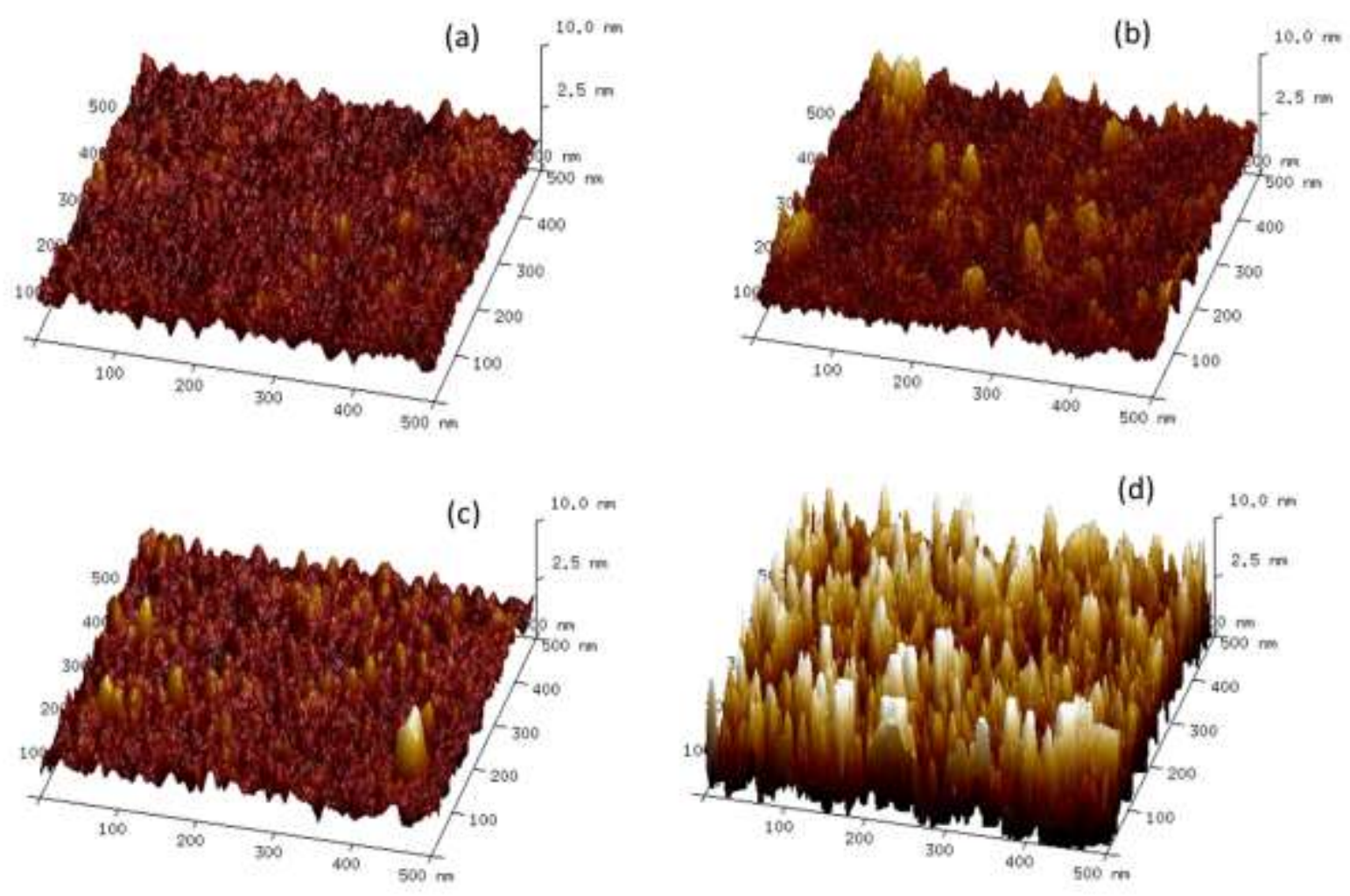

Figure S3. 3D AFM images of (a) non-grafted PET, (b) ozonized PET, (c) thermal grafted PET (tG), and (d) thermal grafted PET in the presence of Mohr's salt (MSG)

Acknowledgment (not applicable)

\section{Declarations of interest}

The authors declare that they have no known competing financial interests or personal relationships that could have appeared to influence the work reported in this paper.

\section{Author Contributions}

Tuan Ngoc Nguyen: principal technical contributor, conception, design and conduct of the experiments, acquisition, analysis, interpretation of data, initial draft the work. Raphaël Lévy: principal technical contributor, analysis, interpretation of data, draft and substantively revised the work. Vincent Humblot: acquisition, analysis, interpretation of data . Véronique 
Migonney: supervisor, project conception, analysis, draft and substantively revised the work.

All authors have approved the submitted version 